Eur. J. Clin. Chem. Clin. Biochem.

Vol. 30, 1992, pp. $729-736$

(C) 1992 Walter de Gruyter \& Co.

Berlin · New York

\title{
Familial Defective Apolipoprotein B-100 in 12 Subjects and Their Kindred
}

\author{
By J. Geisel ${ }^{1}$, T. Schleifenbaum ${ }^{1}, K$. Oette ${ }^{1}$ and B. Weißhaar ${ }^{2}$ \\ ${ }^{1}$ Institut für Klinische Chemie, Universität zu Köln \\ ${ }^{2}$ Max-Planck-Institut für Züchtungsforschung, Abteilung Biochemie, Köln
}

(Received March 2/June 19, 1992)

Summary: Twelve unrelated subjects with heterozygous familial defective apolipoprotein B-100 were identified in a group of 252 patients with type IIa hypercholesterolaemia. Approximately $5 \%$ of hypercholesterolaemia can be explained by this mutation in the collective studied. Familial defective apolipoprotein B-100 is therefore the most common known mutation causing primary hypercholesterolaemia. Family studies revealed an additional 14 affected subjects. All family members with the mutation had elevated cholesterol concentrations. In a normolipidaemic control group of 146 subjects the mutation was not present. In the affected individuals a variable expression of total cholesterol concentrations and atherosclerosis was observed. Plasma cholesterol ranged from 6.60 to $14.89 \mathrm{mmol} / \mathrm{l}$ with a mean of $9.43 \mathrm{mmol} / \mathrm{l}$. Premature atherosclerosis was present in 4 patients, while one affected woman is now 92 years old and has no symptoms of coronary heart disease or peripheral atherosclerosis. Analysis of the haplotypes and genotypes by 3 biallelic and 1 multi-allelic DNA marker suggests that the disorder is caused in all affected patients by the same rare allele. The fact that the same mutant allele was also identified in other European populations and in a North American population of Caucasian origin argues for a common European origin of this mutation.

\section{Introduction}

Familial defective apolipoprotein B-100 is a recently identified, autosomal dominantly inherited genetic disorder which leads to increased serum levels of low density lipoprotein (LDL) cholesterol (1). Apolipoprotein $\mathrm{B}-100$ is the sole protein constituent of LDL particles and is responsible for the recognition of LDL particles by the LDL receptor. In familial defective apolipoprotein B-100, a G to A mutation at nucleic acid 10708 in exon 26 results in the substitution of glutamine for arginine at amino acid position 3500 . This mutation decreases the binding of LDL to the LDL receptor by more than $95 \%$ and causes an accumulation of defective LDL particles in serum (2). The prevalence of familial defective apolipoprotein B100 was estimated to be approximately one in 500 (3-5), making it one of the most common singlegene mutations. The high frequency and the occurrence of the mutation in several different populations raise questions concerning its origin. Because familial defective apolipoprotein B-100 is a recently described disease, only a few subjects have been described in the literature $(3-11)$. The total number of identified unrelated subjects is at the moment less than 100 , worldwide. The apolipoprotein B-100 mutation increases the LDL-cholesterol, but there exists a wide range of LDL-cholesterol levels among the subjects. The plasma of an individual heterozygous for the mutation contains two populations of LDL particles. The increased serum LDL concentration is due to an accumulation of defective LDL particles containing the mutant apolipoprotein B-100. The implications for artherosclerosis of the plasma enrichment of defectively binding LDL particles cannot be determined with certainty from the limited number of identified subjects.

Recently we described a method for identifying subjects with familial defective apolipoprotein B-100 (12). We report here the results of screening 398 subjects. 
The biochemical and clinical data of 12 unrelated subjects heterozygous for familial defective apolipoprotein B-100 and their affected and unaffected family members is presented.

\section{Subjects and Methods}

Subjects

A group of 252 unrelated patients with type IIa hypercholesterolaemia (LDL cholesterol $>4.66 \mathrm{mmol} / \mathrm{l}$ ) were investigated for familial defective apolipoprotein B-100. All individuals were recruited from the outpatient lipid clinic of the Institute of Clinical Chemistry at the University of Cologne. According to their LDL-cholesterol concentration the hypercholesterolaemic patients were divided into three subgroups (tab. 1). By studying the kindred of 8 affected patients, 32 additional subjects were collected and screened for the apolipoprotein B-100 mutation. A second group of 146 normolipidaemic subjects was also studied for familial defective apolipoprotein B-100

Determination of plasma lipids, lipoproteins and apolipoprotein E genotypes

Blood samples were obtained after an overnight fast. Total serum cholesterol, lipoprotein cholesterol and serum triacylglycerols were determined by enzymatic assays (Boehringer, Mannheim, Germany). Very low density lipoproteins (VLDL) were separated by preparative ultracentrifugation according to Havel et al. (13). High density lipoprotein (HDL) cholesterol was determined in the VLDL-free infranatant after precipitation of apolipoprotein B-100-containing lipoproteins (Boehringer, Mannheim, Germany). The apolipoprotein E genotypes were determined by the method of Hixson \& Vernier (14).

\section{Detection of the arginine $\mathrm{e}_{(3500)} \rightarrow$ glutamine mutation}

Genomic DNA was prepared from total blood by using the Triton X-100 lysis method (15). DNA was amplified by the polymerase chain reaction and the $G$ to $A$ mutation at nucleic acid 10708 was detected by restriction enzyme isoform genotyping. The method employed was recently described in detail (12).

\section{Determination of genotypes}

Four DNA markers were used for the genotyping. These markers consisted of 3 biallelic restriction fragment length polymorphism markers (XbaI, MspI, EcoRI) $)^{1}$ and a multi-allelic marker (fig. 1). The restriction fragment length polymorphism markers were assayed by polymerase chain reaction and digestion with the restriction enzymes, following agarose gel electrophoresis. The multi-allelic marker consisted of a variable number of tandem repeats. The number of repeats was determined by agarose gel electrophoresis. The used nomenclature applied for the 3'hypervariable region was that of Boerwinkle et al. (16). If family members of an identified subject were available, haplotypes were constructed by analysis of segregation of the polymorphic sites. All polymerase chain reactions were carried

\footnotetext{
1) Enzymes

Taq DNA polymerase from Thermus aquaticus, EC 2.7.7.7

Restriction endonucleases EC 3.1.21.-

EcoRI from Escherichia coli BS5

XbaI from Xanthomonas campestris

MspI from Acinotobacter lwoffii

Moraxella species
}

out in a final volume of $100 \mu \mathrm{l}$ using $1 \mu \mathrm{g}$ DNA, $0.25 \mathrm{mmol} / \mathrm{l}$ of each nucleotide, 2.5 units Taq-polymerase ${ }^{1}$ ) (Perkin-Elmer Cetus, Langen, Germany) and the buffer recommended by the manufacturer of the Taq polymerase. For the $X b a I-$ and EcoRIpolymerase chain reaction $0.2 \mu \mathrm{mol} / 1$ and $0.4 \mu \mathrm{mol} / 1$ primer were used; for the MspI-polymerase chain reaction and the hypervariable region-polymerase chain reaction $0.15 \mu \mathrm{mol} / 1$ and $0.1 \mu \mathrm{mol} / 1$, respectively. The primer sequences are described elsewhere $(1,16-18)$. The initial denaturation was at $94^{\circ} \mathrm{C}$ for 2 minutes, followed by annealing at $55^{\circ} \mathrm{C}$ for 1 minute and extension at $72^{\circ} \mathrm{C}$ for 1 minute. The next 30 cycles were performed in the same way, except that the denaturing time was changed to 1 minute.

\section{Results}

The $\operatorname{arginine}_{(3500)} \rightarrow$ glutamine mutation was not detected in the normolipidaemic group. In the hypercholesterolaemic group, 12 patients were identified who were heterozygous for familial defective apolipoprotein B-100 (tab. 1). The mutation was found in all 3 subgroups of LDL-cholesterol concentration. Relatives of 8 subjects were available for family studies. Within these families we identified 14 additional subjects with the apolipoprotein B-100 mutation. The biochemical characteristics and the clinical signs of atherosclerosis of the 12 index patients, their relatives with familial defective apolipoprotein B-100 and their unaffected relatives are summarized in table 2. All affected subjects had elevated total cholesterol concentrations in plasma. The cholesterol concentrations ranged from $6.60 \mathrm{mmol} / 1$ to $14.89 \mathrm{mmol} / 1$, mean value $9.43 \mathrm{mmol} / \mathrm{l}$. Hyperlipidaemia was also found in subjects without familial defective apolipoprotein B-100. In 2 subjects, one from the F. S. family and the other from the E.K. family, hyperlipidaemia might be secondarily caused by diabetes mellitus. The subject from the W. E. family had moderate hypercholesterolaemia which was first manifest postmenopausal. Hypercholesterolaemia of other causes was also observed in the H. K. and H. A. family. Premature atherosclerosis was found in 4 of the 26 subjects with familial defective apolipoprotein B-100. Severe coronary obstructions warranted, in 3 patients, a coronary artery bypass graft. The age of operation was 52 and 60 for the two females and 20 for the male. The fourth patient had suffered a myocardial infarction at age 61 . The oldest patient was 92 years of age and had no symptoms of coronary heart disease or peripheral atherosclerosis. In the unrelated probands, arcus cornea was present in $45 \%$, and xanthoma of the Achilles tendon or the extensor tendon of the finger were found in $36 \%$.

In an attempt to find the reason for the variable degree of LDL-cholesterol elevation we determined the apolipoprotein $\mathrm{E}$ genotypes in the 26 affected patients (tab. 2). One patient had the genotype E2/ 


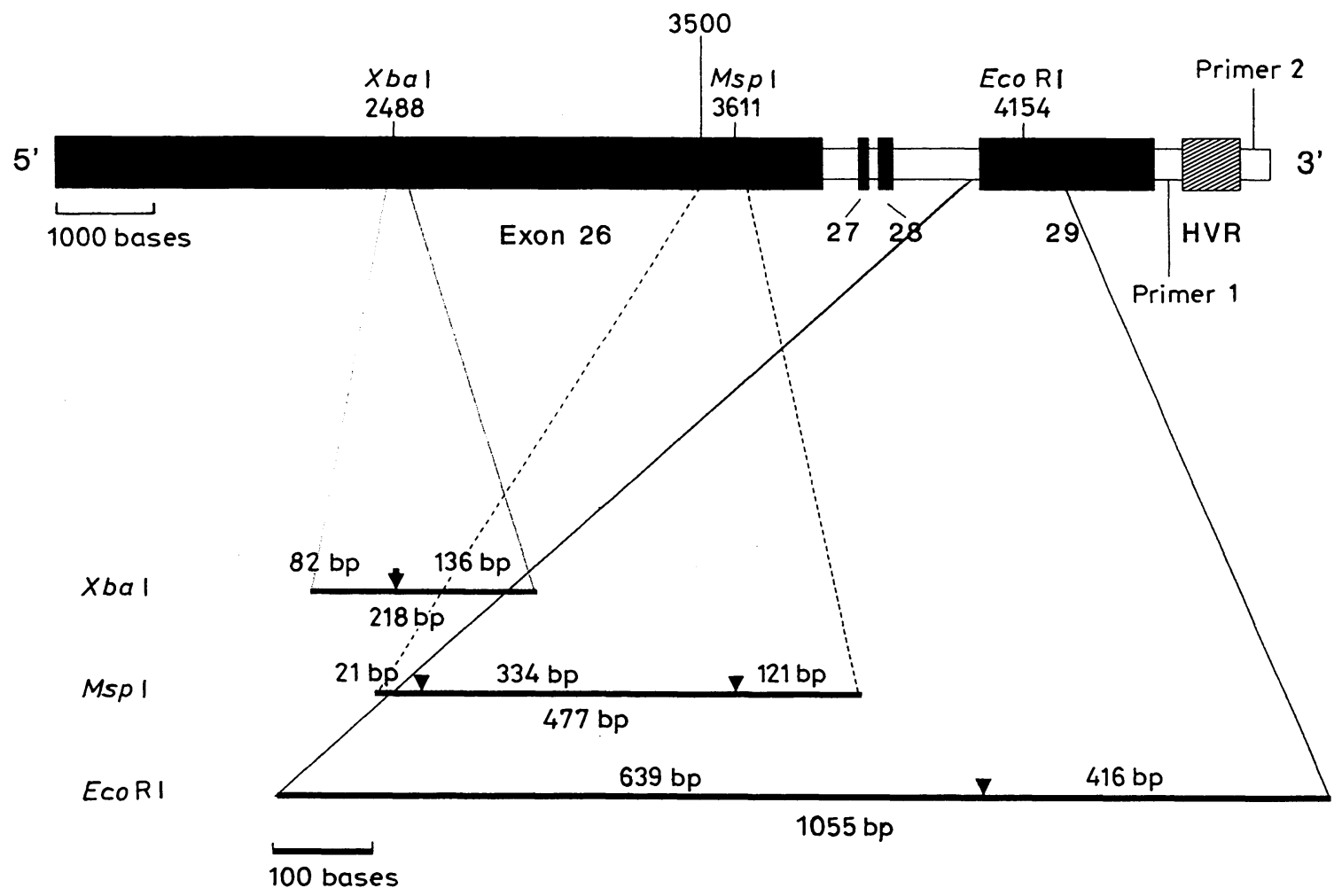

Fig. 1. DNA markers for the 3 '-end of the human apolipoprotein B-100 gene.

In the upper portion, the position of the restriction fragment length polymorphisms, the mutation and the hypervariable region (HVR) are shown. The lower portion shows the length of the polymerase chain reaction fragments in base pairs (bp) before and after digestion with the appropriate restriction enzyme.

Tab. 1. Prevalence of familial defective apolipoprotein B-100 in normolipidaemic and hypercholesterolaemic individuals

\begin{tabular}{lcccc}
\hline & $\begin{array}{l}\text { Number of } \\
\text { screened subjects }\end{array}$ & \multicolumn{2}{l}{ Frequency of mutation } \\
\cline { 3 - 5 } & & absolute & relative (\%) \\
\hline Normolipidaemic subjects & 146 & 0 & 4.8 \\
Hypercholesterolaemia type IIa & 252 & 12 & 5.2 \\
LDL-cholesterol: & $4.69-5.70 \mathrm{mmol} / \mathrm{l}$ & 58 & 3 & 1.8 \\
LDL-cholesterol: $5.71-6.73 \mathrm{mmol} / 1$ & 57 & 8 & 5.8 \\
LDL-cholesterol: $>6.73 \quad \mathrm{mmol} / \mathrm{l}$ & 137 & 8 & 8 \\
\hline
\end{tabular}

E3. The most common genotype E3/E3 was detected in 21 subjects. In 3 cases the genotype E3/E4 and in one case the genotype E4/E4 was present. The group of subjects with the genotype E3/E3 included patients with moderate and severe hypercholesterolaemia. Therefore the apolipoprotein E genotype is not responsible for the variability of LDL cholesterol elevation in these patients.

The haplotypes were determined by 3 diallelic markers and one hypervariable multi-allelic marker (fig. 1). The hypervariable region at the 3 '-end of the gene comprises 12 resolvable alleles containing different numbers of 15-base pair tandemly repeated sequences. The analysis of haplotypes of the 8 kindred is illustrated in figure 2 . In 7 of the 8 families the haplotypes of the mutant allele were determined unambiguously. The haplotypes of the mutant were in all cases identical, characterized by the presence of the $M s p I$ restriction site $\left(\mathrm{MspI}^{+}\right)$, the absence of the $\mathrm{XbaI}\left(\mathrm{XbaI}^{-}\right)$ and $E c o$ RI $\left(E c o \mathrm{RI}^{-}\right)$restriction sites and 49 of the 15 base pair repeats of the hypervariable region (HVR-49). In the remaining 5 individuals with familial defective apolipoprotein B-100, the combination of genotypes was consistent with the presence of the mutation on the above described haplotype. 


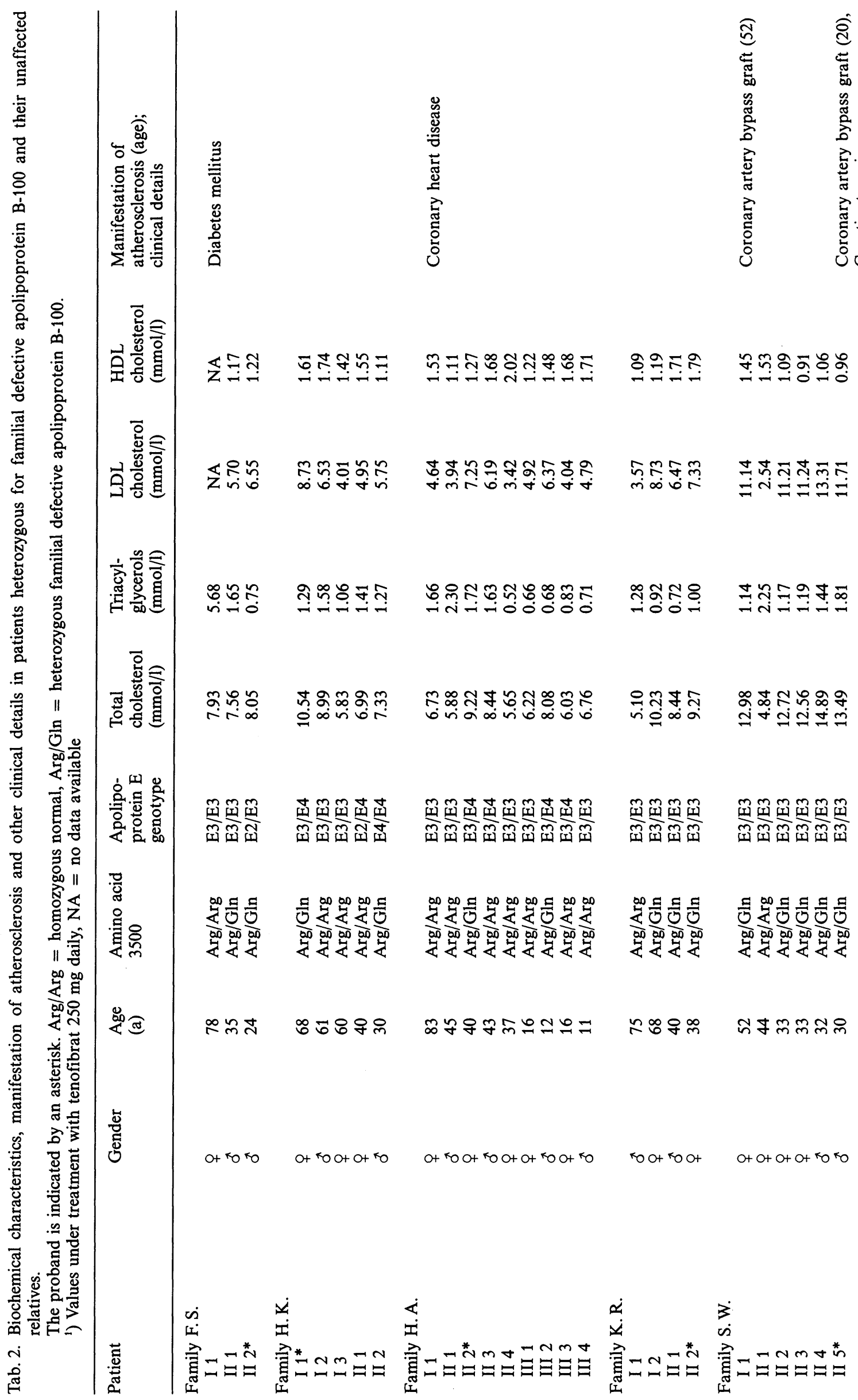




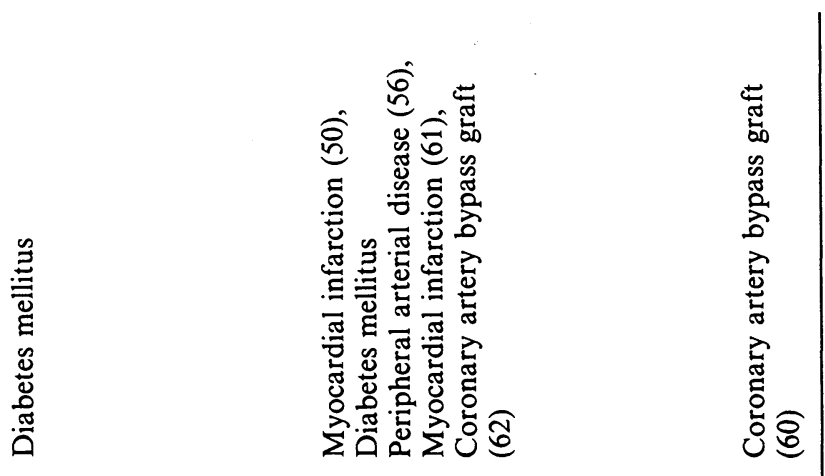

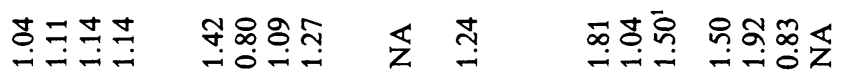

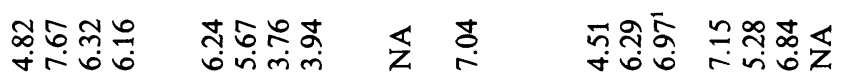

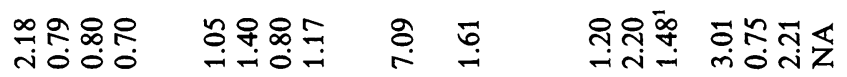

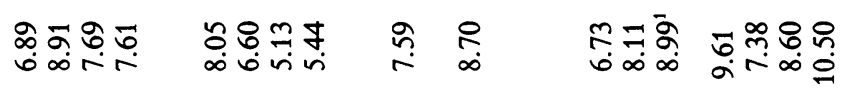

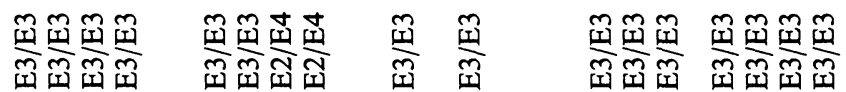

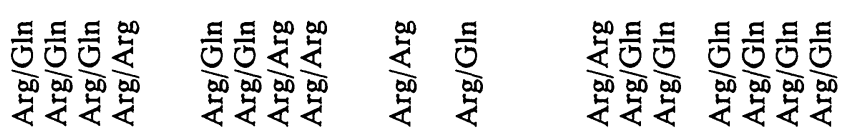

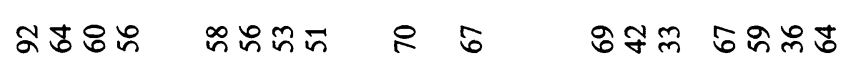

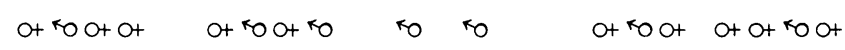

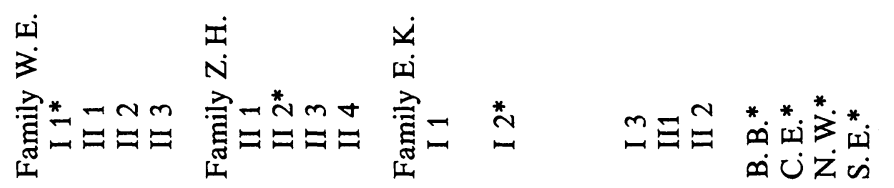

Eur. J. Clin. Chem. Clin. Biochem. / Vol. 30, 1992 / No. 11 


\section{Kindred of F.S.}

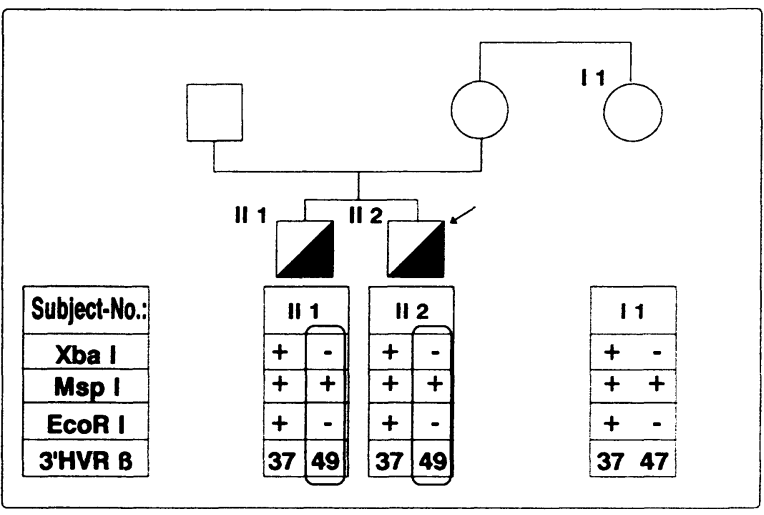

Kindred of H.A.

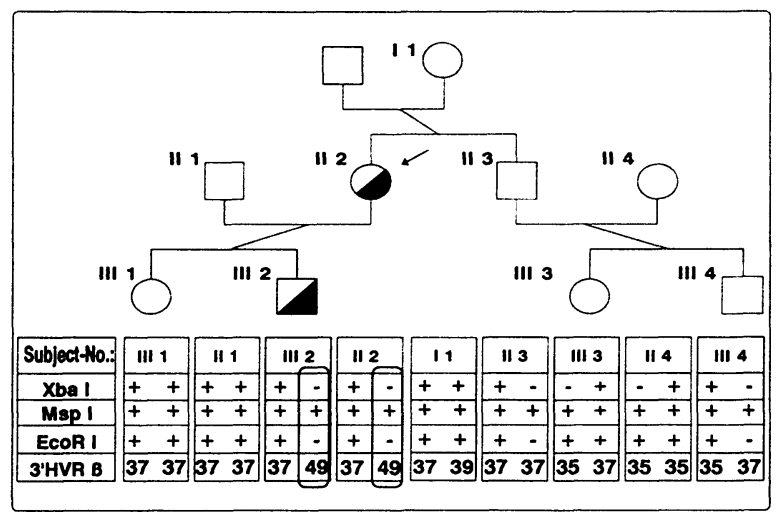

Kindred of S.W.

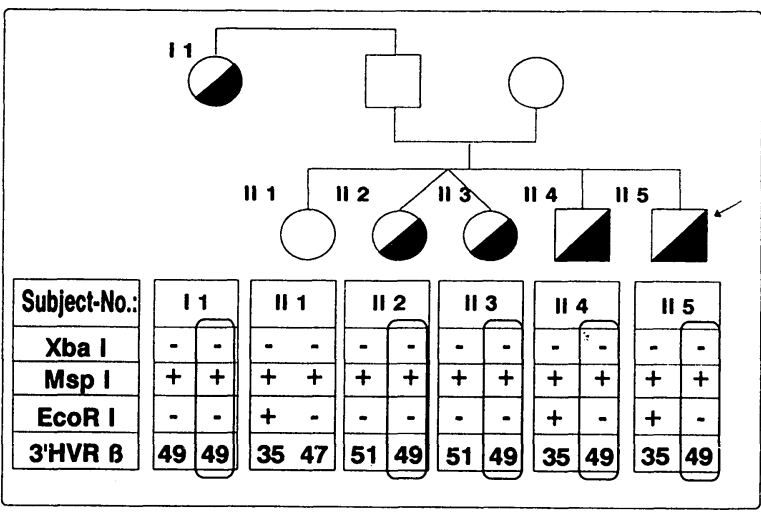

Kindred of Z.H.

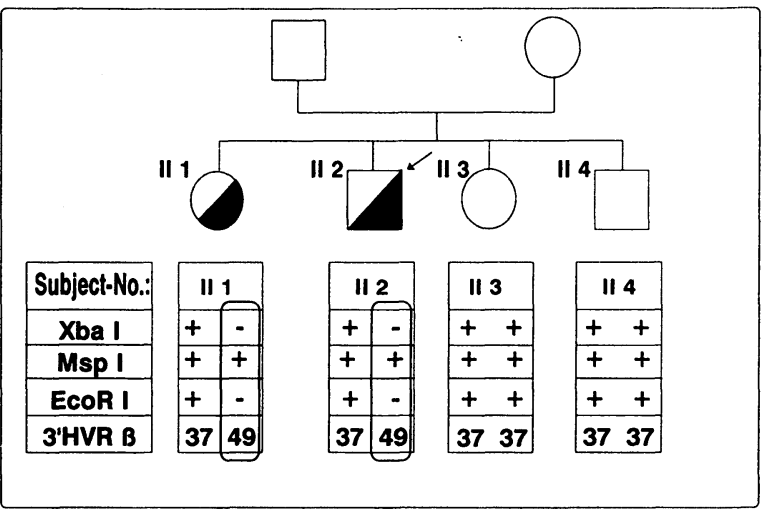

Kindred of H.K.

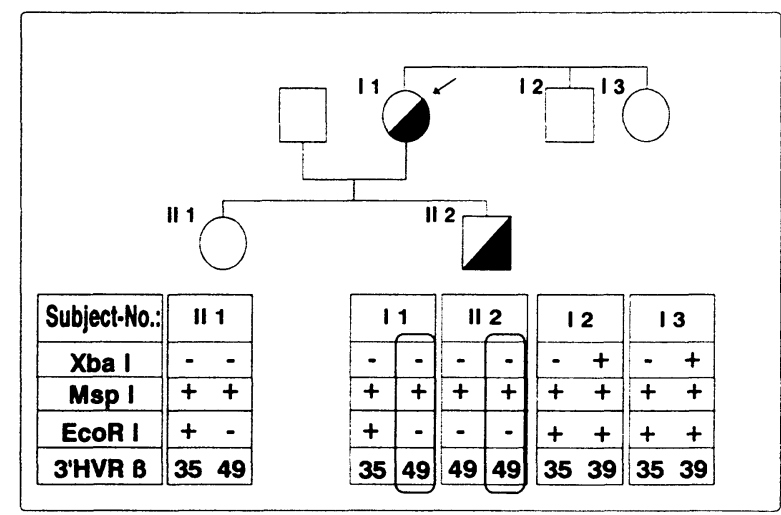

Kindred of K.R.

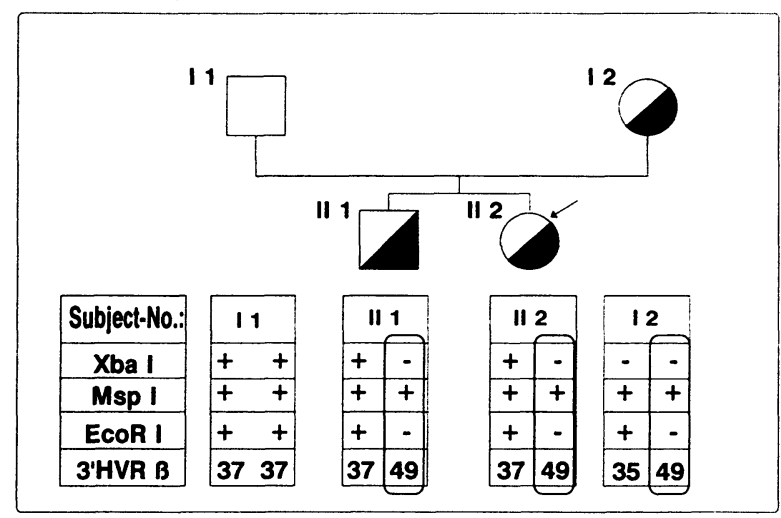

Kindred of W.E.

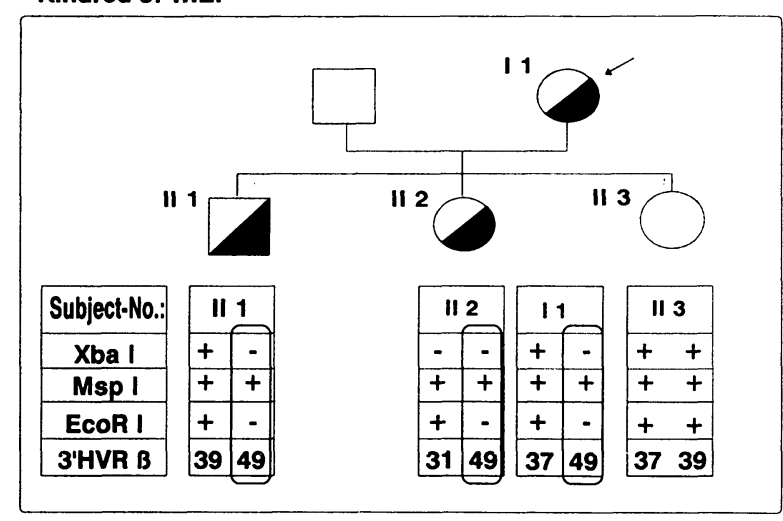

Kindred of E.K.

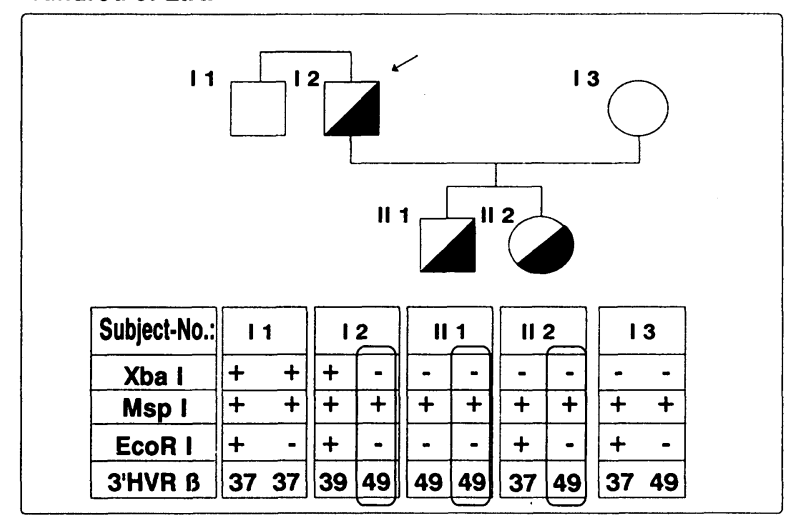

Fig. 2. Pedigrees and haplotype analysis of the 8 kindred with familial defective apolipoprotein B-100.

The haplotypes were constructed by analysis of segregation of 3 biallelic DNA markers (XbaI, MspI, EcoRI) and one hypervariable multi-allelic marker ( $3^{\prime}$ hypervariable region, $3^{\prime} \mathrm{HVR} \beta$ ). The haplotype of the mutant allele is encircled. The available subjects in the families are numbered. Heterozygous familial defective apolipoprotein B-100 is shown by halfshadowed symbols. The arrow indicates the index patients. The biochemical data are presented in table 2. 


\section{Discussion}

With the recently described modified polymerase chain reaction technique (12) we screened 252 unrelated individuals with hypercholesterolaemia and 146 normolipidemic controls. In the hypercholesterolaemic group 12 unrelated individuals heterozygous for familial defective apolipoprotein B-100 were identified. The frequency of the mutation was, therefore, about $5 \%$ in the hypercholesterolaemic group. In normolipidaemic subjects the mutation was not detected. Assuming a frequency of type IIa hypercholesterolaemia of $5 / 100$ (19), a crude estimate of the frequency of familial defective apolipoprotein B-100 would be $1 / 400$ in the general population and is thus similar to the frequency of familial hypercholesterolaemia which is characterized by defects in the LDLreceptor.

The study of biochemical characteristics and signs of atherosclerosis revealed a considerable variability of expression in patients with heterozygous familial defective apolipoprotein B-100, exemplified by patients W. E. and S. W. (tab. 2). S. W. had severe hypercholesterolaemia and premature atherosclerosis. He warranted a coronary bypass graft at age 20 and had stenosis of the carotis. In contrast, W.E. had only moderate hypercholesterolaemia, the total cholesterol concentrations ranging in the last 10 years from 5.70 to $7.25 \mathrm{mmol} / \mathrm{l}$. Over the whole period she was treated only with diet. Her HDL-cholesterol concentration was at the lower end of the reference range for women. The patient is now 92 years old and has no symptoms of coronary heart disease or peripheral atherosclerosis. Obviously, in patients with familial defective apolipoprotein B-100, atherosclerosis was more advanced in those with severe hypercholesterolaemia than in patients with moderate hypercholesterolaemia. In addition to hypercholesterolaemia, other risk factors, such as smoking as seen in patients S.W. and E. K., may contribute to the progression of atherosclerosis. In summary, it is not the apolipoprotein B100 mutation per se but the degree of cholesterol elevation and the combination with other risk factors that seem to determine the atherosclerosis risk.

Premature atherosclerosis was found in only 4 out of 26 cases. Compared with the atherosclerosis risk of familial hypercholesterolaemia (20), it seems that the risk in patients with familial defective apolipoprotein B-100 might be somewhat lower, even in patients with severe hypercholesterolaemia. For example, atherosclerosis was present in only one of 4 females older than 60 years with total cholesterol concentrations near or above $10.36 \mathrm{mmol} / \mathrm{l}$. In familial hypercholesterolaemia, HDL cholesterol concentrations are slightly lower on the average than those in normal subjects (20). In the patients studied with familial defective apolipoprotein B-100, the mean HDL cholesterol was $1.26 \mathrm{mmol} / \mathrm{l}$ and is thus similar to that of normal subjects. The higher HDL-cholesterol concentration of subjects with familial defective apolipoprotein B-100 in comparison with familial hypercholesterolaemia might be a reason for the possibly lower atherosclerosis risk. However, more patients have to be evaluated to estimate the atherosclerosis risk.

The variability of biochemical and clinical characteristics within families was much less than between unrelated subjects. For example, in the S.W. family all affected persons had severe hypercholesterolaemia, and premature atherosclerosis was present in a second case (tab. 2). On the other hand, all affected individuals of the W.E. family had total cholesterol concentrations below the mean value of the unrelated affected subjects, and in 2 cases the concentrations were even below the 95th percentile (19). In this family the affected individuals were more than 60 years old and no symptoms of atherosclerosis were observed. In an attempt to find reasons for the variable expression of LDL-cholesterol levels we determined the apolipoprotein $\mathrm{E}$ genotypes, but a consistent relation between the concentration of LDL-cholesterol and the apolipoprotein $\mathrm{E}$ genotype was not observed. The apolipoprotein E genotype E3/E3 was detected in 21 subjects. This group contained individuals with moderate and severe hypercholesterolaemia. At the moment it can only be speculated as to which factors influence the expression of familial defective apolipoprotein B100 in these patients. But the existence of a relatively large number of affected individuals provides an excellent model for studying the influence of other gene loci and environmental factors on the level of LDL cholesterol and atherosclerosis.

The families of 8 index patients were studied to determine the haplotype of the arginine $_{(3500)} \rightarrow$ glutamine mutation (fig. 2). Seven of the 8 families were informative, and the mutation could be assigned to the haplotype $\mathrm{XbaI}^{-}, \mathrm{Msp}^{+}, \mathrm{EcoR \textrm {R } ^ { - }}$ and HVR-49. In the remaining 5 index patients, the combination of genotypes was consistent with the described haplotype. Because the haplotype of the mutation is very rare (21), it is likely that the mutation arose from a single origin, rather than being the result of random mutations. Identical haplotypes of the mutation have also been described in other European populations $(6,8,9)$ and in a North American population of European origin $(3,17)$. This suggests that the mutation has a common European origin. The mutation was not detected in the genetically isolated population of Finland (22). Further studies of the frequency will show whether a founder population exists in Europe. 


\section{References}

1. Soria, L. F., Ludwig, E. H., Clarke, H. R. G., Vega, G. L., Grundy, S. M. \& McCarthy, B. J. (1989) Association between a specific apolipoprotein B mutation and familial defective apolipoprotein B-100. Proc. Natl. Acad. Sci. USA $86,587-591$

2. Innerarity, T. L., Balestra, M. E., Arnold, K. S., Mahley, R. W., Vega, G. L., Grundy, S. M. \& Young, S. G. (1988) Isolation of defective receptor-binding low density lipoproteins from subjects with familial defective apolipoprotein B-100. Arteriosclerosis 8, 551a.

3. Innerarity, T. L., Mahley, R. W., Weisgraber, K. H., Bersot, T. P., Krauss, R. M., Vega, G. L., Grundy, S. M., Friedl, W., Davignon, J. \& McCarthy, B. J. (1990) Familial defective apolipoprotein B-100: A mutation of apolipoprotein B that causes hypercholesterolemia. J. Lipid. Res. 31, $1337-1349$

4. Schuster, H., Rauh, G., Kormann, B., Hepp, T., Humphries, S., Keller, C., Wolfram, G. \& Zöllner, N. (1990) Familial defective apolipoprotein B-100: Comparison with familial hypercholesterolemia in 18 cases detected in Munich. Arteriosclerosis 10, 577-581.

5. Tybjærg-Hansen, A., Gallagher, J., Vincent, J., Houlston, R., Talmud, P., Dunning, A. M., Seed, M., Hamsten, A., Humphries, S. E. \& Myant, N. B. (1990) Familial defective apolipoprotein B-100: Detection in the United Kingdom and Scandinavia, and clinical characterics of ten cases. Atherosclerosis $80,235-242$.

6. Friedl, W., Ludwig, E. H., Balestra, M. E., Arnold, K. S., Paulweber, B., Sandhofer, F., McCarthy, B. J. \& Innerarity, T. L. (1991) Apolipoprotein B gene mutations in Austrian subjects with heart disease and their kindred. Arterioscler. Thromb. 11, 371-378.

7. Corsini, A., McCarthy, B. J., Granata, A., Soria, L. F., Fantappiè, S., Bernini, Romano, C., Romano, L., Fumagalli, R. \& Catapano, A. L. (1991) Familial defective apo B-100, characterization of an Italian family. Eur. J. Clin. Invest. 21, 389-397.

8. Myant, N. B., Gallagher, J. J., Knight, B. L., McCarthy, S. N., Frostegard, J., Nilsson, J., Hamsten, A., Talmud, P. \& Humphries, S. E. (1991) Clinical signs of familial hypercholesterolemia in patients with familial defective apolipoprotein B-100 and normal low density lipoprotein receptor function. Arterioscler. Thromb. 11, 691-703.

9. Rauh, G., Schuster, H., Fischer, J., Keller, C., Wolfram, G. \& Zöllner, N. (1991) Familial defective apolipoprotein B-100: haplotype analysis of the $\operatorname{argine}_{(3500)} \rightarrow$ glutamine mutation. Atherosclerosis 88, 219-226.

10. Rauh, G., Schuster, H., Fischer, J., Keller, Ch., Wolfram, G. \& Zöllner, N. (1991) Identification of a heterozygous compound individual with familial hypercholesterolemia and familial defective apolipoprotein B-100. Klin. Wochenschr. $69,320-324$.
11. Hosking, J. L., Bals, R., Roach, P. D. \& Thomas, D. W. (1991) Hypercholesterolemia due to familial defective apolipoprotein B-100 in two Australian families. Med. J. Australia $155,572-573$.

12. Geisel, J., Schleifenbaum, T., Weißhaar, T. \& Oette, K. (1991) Rapid diagnosis of familial defective apolipoprotein B-100. Eur. J. Clin. Chem. Clin. Biochem. 29, 395-399.

13. Havel, R., Eder, H. \& Bragdon, J. (1955) The distribution and chemical composition of ultracentrifugally separated lipoproteins in human serum. J. Clin. Invest. 34, 13451353.

14. Hixson, J. E. \& Vernier, D. T. (1990) Restriction isotyping of human apolipoprotein $\mathrm{E}$ by gene amplification and cleavage with HhaI. J. Lipid. Res. $31,545-548$.

15. Kunkel, L. M., Smith, K. D., Boyer, S. H., Borgaonkar, D. S., Wachtel, S. S., Miller, O. J., Breg, W. R., Jones, H. W. \& Rary, J. M. (1977) Analysis of human Y-chromosome-specific reiterated DNA in chromosome variants. Proc. Natl. Acad. Sci. USA 74, 1245-1249.

16. Boerwinkel, E., Xiong, W., Fourest, E. \& Chan, L. (1989) Rapid typing of tandemly repeated hypervariable loci by the polymerase chain reaction: Application to the apolipoprotein B 3 'hypervariable region. Proc. Natl. Acad. Sci. USA 86, 212-216.

17. Ludwig, E. H. \& McCarthy, B. J. (1990) Haplotype analysis of the human apolipoprotein B mutation associated with familial defective apolipoprotein B100. Am. J. Hum. Genet. 47, 712-720.

18. Motti, C., Funke, H., Rust, S., Dergunov, A. \& Assmann, G. (1991) Using mutagenic polymerase chain reaction primers to detect carriers of familial defective apolipoprotein B-100. Clin. Chem. 37, 1762-1766.

19. Henze, K., Wallmüller-Strycker, A., Bauer, M., Barth, C., Wolfram, G. \& Zöllner, N. (1981) Cholesterin and Triglyceride im Serum einer Münchner Bevölkerungsgruppe: Beziehungen zu Alter und Geschlecht. J. Clin. Chem. Clin. Biochem. 19, 1013-1019.

20. Goldstein, J. L. \& Brown, M. S. (1983) Familial hypercholesterolemia. In: The metabolic basis of inherited disease (Stanbury, J. B., Wyngaarden, J. B., Frederickson, D. S., Goldstein, J. L. \& Brown, M. S., eds.) 5th edn., McGrawHill, New York.

21. Friedl, W., Ludwig, E. H., Paulweber, B., Sandhofer, F. \& McCarthy, B. J. (1990) Hypervariability in a minisatellite $3^{\prime}$ of the apolipoprotein B gene in patients with coronary heart disease compared with normal controls. J. Lipid Res. $31,659-665$.

22. Hämäläinen, T., Palotie, A., Aalto-Setälä, K., Kontula, K. \& Tikkanen, M. J. (1990) Absence of familial defective apolipoprotein B-100 in Finnish patients with elevated serum cholesterol. Atherosclerosis 82, 177-183.

\author{
Dr. J. Geisel \\ Institut für Klinische Chemie \\ Universität zu Köln \\ Joseph-Stelzmann-Straße 9 \\ W-5000 Köln 41 \\ Bundesrepublik Deutschland
}

